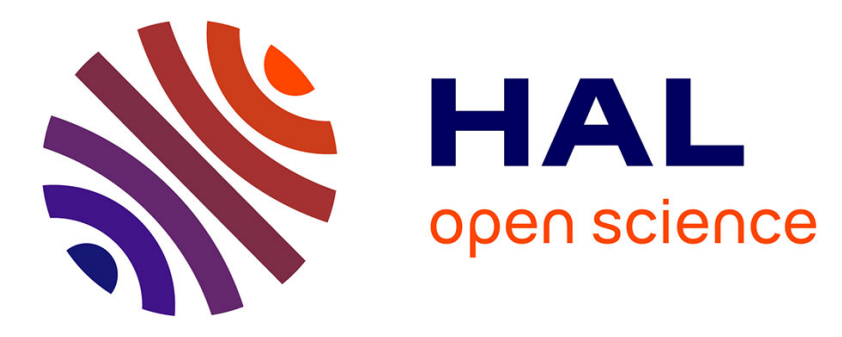

\title{
Pentamethylcyclopentadienyl Iridium(III) Metallacycles Applied to Homogeneous Catalysis for Fine Chemical Synthesis
}

\author{
Christophe Michon, Kirsty Macintyre, Yann Corre, Francine
}

Agbossou-Niedercorn

\section{To cite this version:}

Christophe Michon, Kirsty Macintyre, Yann Corre, Francine Agbossou-Niedercorn. Pentamethylcyclopentadienyl Iridium(III) Metallacycles Applied to Homogeneous Catalysis for Fine Chemical Synthesis. ChemCatChem, 2016, 8 (10), pp.1755 - 1762. 10.1002/cctc.201600238 . hal-01715063

\section{HAL Id: hal-01715063 \\ https://hal.science/hal-01715063}

Submitted on 2 Jan 2022

HAL is a multi-disciplinary open access archive for the deposit and dissemination of scientific research documents, whether they are published or not. The documents may come from teaching and research institutions in France or abroad, or from public or private research centers.
L'archive ouverte pluridisciplinaire HAL, est destinée au dépôt et à la diffusion de documents scientifiques de niveau recherche, publiés ou non, émanant des établissements d'enseignement et de recherche français ou étrangers, des laboratoires publics ou privés. 


\title{
Pentamethylcyclopentadienyl iridium(III) metallacycles applied to homogeneous catalysis for fine chemicals synthesis
}

\author{
Christophe Michon, ${ }^{*[a, b]}$ Kirsty MacIntyre, ${ }^{[a, b]}$ Yann Corre, ${ }^{[a, b]}$ Francine Agbossou-Niedercorn, ${ }^{*[a, b]}$
}

\begin{abstract}
While pentamethylcyclopentadienyl cyclometallated complexes have been used to catalyse a variety of organic transformations over the last decades, the huge potential of pentamethylcyclopentadienyl iridacycles has recently been truly recognised. In the past years, an upsurge of reports on such new half-sandwich iridium(III) metallacycles could be observed. Their application in various homogeneous catalysed organic reactions has led to the development of environmentally and economically beneficial routes to important and highly functionalised fine chemicals. Studied reactions include hydrogenation, amine alkylation, dehydrogenation, oxidation and hydrofunctionalization reactions as well as dynamic kinetic resolutions (DKR). This minireview focusses specifically on the recent applications of halfsandwich iridium(III) metallacycles in such processes.
\end{abstract}

\section{Introduction}

The cyclometallation reaction, discovered in early 1960's, has become a unique synthetic tool in organometallic chemistry. ${ }^{[1,2]}$ Indeed, cyclometallation provides access to original organometallic compounds bearing a metal-carbon $\sigma$ bond. Such complexes are synthesised via C-H (or C-C) bond activation of a ligand which is assisted intramolecularly by coordination of a directing donor atom $(\mathrm{N}, \mathrm{P}, \mathrm{O}, \mathrm{C} \ldots)$. Thus, the resulting metallacycle consists of a metal bound to a chelate carboligand which not only provides increased stability to the complex, but also exclusive reactivity. ${ }^{[1,2]}$ Most significantly, transition-metal-catalysed $\mathrm{C}-\mathrm{H}$ activation has allowed various ortho-selective $\mathrm{C}-\mathrm{C}$ and $\mathrm{C}-\mathrm{X}$ bond-forming reactions through insitu generation of metallacycle intermediates. ${ }^{[3]}$ Compared to their ruthenium and rhodium counterparts, iridacycles have been far less studied ${ }^{[4]}$ but have attracted a rising interest these past years. More specifically, half-sandwich (i.e. pentamethylcyclopentadienyl) iridium(III) metallacycles have demonstrated a great potential in homogeneous catalysis displaying significant activities for a range of organic reactions. Meanwhile, iridacycles have also attracted a great interest in photochemistry due to their photophysical properties. ${ }^{[5]}$ Further applications of iridium(III) metallacycles have been reported in biology as antibacterial and anticancer agents ${ }^{[6]}$ as well as in other reactivity studies. ${ }^{[7,8]}$ Indeed, half-sandwich iridium(III) metallacycles have been recently applied in energy and environmental science to catalyse reactions such as: dehydrogenation and oxidation of formic acid, hydrogenation of carbonates, productions of hydrogen or hydrogen peroxide. ${ }^{[8]}$

All these complementary properties and applications

of

[a] Dr. C. Michon, K. MacIntyre, Y. Corre, Dr. F. Agbossou-Niedercorn, Univ. Lille, CNRS, Centrale Lille, ENSCL, Univ. Artois, UMR 8181 UCCS - Unité de Catalyse et Chimie du Solide, F-59000 Lille, France.

E-mail: christophe.michon@ensc-lille.fr, francine.agbossou@ensc-lille.fr

[b] ENSCL, UCCS-CCM-CASECO, (Chimie-C7) CS 90108, 59652 Villeneuve d'Ascq Cedex, France iridacycles will not be detailed herein. This minireview summarises recently developed homogeneous catalysed organic chemical reactions employing half-sandwich iridium(III) cyclometallated complexes as catalysts in hydrogenation, amine alkylation, dehydrogenation, oxidation and hydrofunctionalization reactions as well as dynamic kinetic resolutions (DKR).

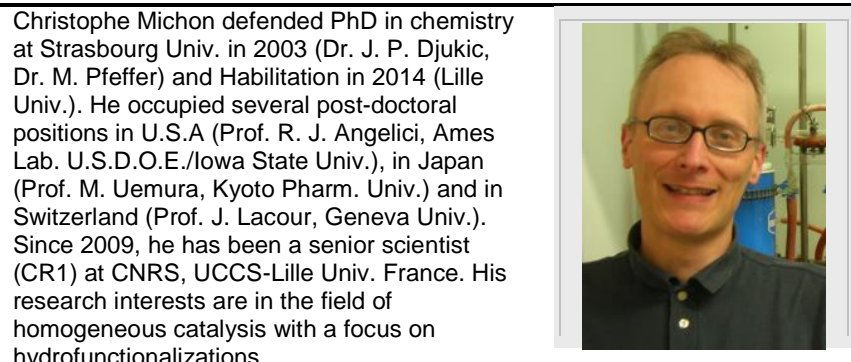
hydrofunctionalizations.

Kirsty Maclntyre is a Master student studying chemistry at The University of Edinburgh, Scotland. Since fall 2015, she has been participating in the Chemistry $4 \mathrm{MX}$ course taken as the 4th year of the MChem Year Abroad degree program with ERASMUS and the ENSCL. Her present research focusses on the synthesis of chiral $\mathrm{N}$-Heterocyclic Carbene ligands and their organometallic complexes with applications in homogeneous catalysis.

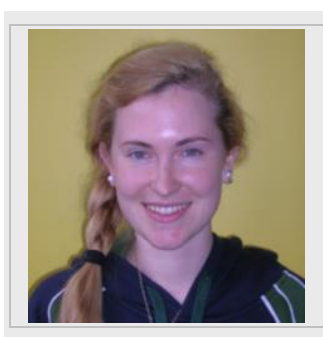

Yann Corre is Doctor in Pharmacy from Rennes Univ. After a Master training period at Tohoku Univ. (Japan) within Prof. Y.

Yamamoto laboratory, he started his PhD at Lille Univ., working with Dr. F. AgbossouNiedercorn and Dr. C. Michon on the hydrosilylation of unsaturated carbonheteroatom bonds catalysed by iridium(III) metallacycles. After his defense by fall 2015 he has accepted a post-doctoral position in medicinal chemistry at Grenoble Univ.

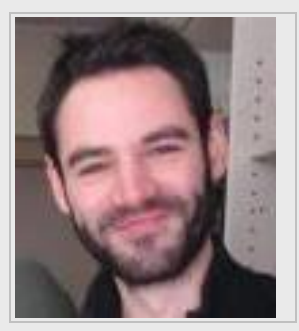

Francine Agbossou-Niedercorn obtained he $\mathrm{PhD}$ in the field of porphyrin chemistry. Afterwards, she took a research fellow position with the CNRS in IRCELYON (Villeurbanne) on Cytochrome P450 models. In 1985, she joined the LCC (Toulouse) and got involved in homogeneous catalysis (hydration, amination, oxidation). After a postdoctoral stay at the University of Utah in Salt Lake City with Prof. J. A. Gladysz, she joined UCCS (Lille) in 1991. Since 2010, she is leader of the Department of Catalysis and Molecular Chemistry of UCCS. Her research interests focus on homogeneous catalysis and asymmetric synthesis.

\section{Hydrogenation, transfer hydrogenation, reductive amination}

\subsection{Hydrogenation}

In 2013, a series of half-sandwich iridium(III) metallacycles was investigated by Xiao et al. to catalyse the hydrogenation of $\mathrm{C}=\mathrm{N}$ containing substrates (Scheme 1). ${ }^{[9]}$ After a thorough screening of $\mathrm{C}-\mathrm{N}$ chelate ligands, the optimized catalyst was applied in the hydrogenation of a large 
scope of imines and N-heterocyclic substrates. The use of 2,2,2trifluoroethanol (TFE) meant effective chloride dissociation without the use of a halide abstraction agent allowing $\mathrm{H}_{2}$ coordination to proceed. The catalyst developed was effective in the chemoselective reduction of various cyclic and acyclic imines as well as $\mathrm{N}$-heteroaromatic substrates like quinoxalines and unprotected indoles.

$$
\begin{aligned}
& \mathrm{R}_{1}=\mathrm{H} \text {, alkyl or phenantroline, acridine. } \\
& \mathrm{R}_{2}=\mathrm{H} \text {, alkyl, ester, halide... } \\
& \mathrm{R}_{3}, \mathrm{R}_{4}=\mathrm{H} \text {, OMe ; } \mathrm{R}_{5}=\text { alkyl, aryl } \\
& \text { as well as quinoxaline, indole and styrene derivatives }
\end{aligned}
$$

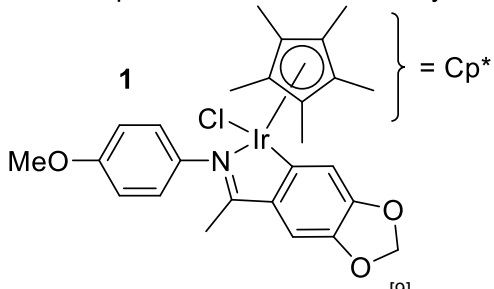

Scheme 1. Hydrogenation of $\mathrm{C}=\mathrm{N}$ bonds. ${ }^{[9]}$

More recently, the modification of such iridacycles was reported to facilitate the hydrogenation of imines at low catalyst loadings (Scheme 2). ${ }^{[10]}$ They observed substrates with electron donating groups were hydrogenated more efficiently than those bearing electron withdrawing substituents.

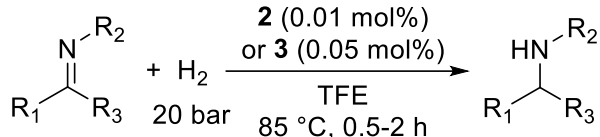

$$
\begin{aligned}
& \mathrm{R}_{1}=\text { aryl, alkyl } \\
& \mathrm{R}_{2}=\text { aryl, benzyl, alkyl } \\
& 34 \text { examples }
\end{aligned}
$$$$
\mathrm{R}_{3}=\text { alkyl, } \mathrm{H}
$$<smiles>COc1ccc(N2C(C)=C3c4ccc([N+](=O)[O-])cc4[I-](Cl)([Pb])[C@]32C(C)=O)cc1</smiles>

Scheme 2. Hydrogenation of imines. ${ }^{[10]}$

The reaction of a ketimine was scaled up to $2 \mathrm{~g}$ using $0.01 \mathrm{~mol} \%$ of 2 , at $85^{\circ} \mathrm{C}$ in $2 \mathrm{~h}$ and afforded the related amine in $93 \%$ yield.

\subsection{Transfer hydrogenation}

Transfer hydrogenation has been applied by Xiao et al. in the presence of half-sandwich iridium(III) metallacycles for the reduction of imines with formic acid. ${ }^{[11]}$ The mechanistic aspects of the reaction were studied in detail through kinetic experiments and DFT calculations. Two key steps of the mechanism have been particularly scrutinized i.e. formation of the metal hydride (rate determining) and hydride transfer to the substrate (Figure 1). Beside the 3 possible pathways for the synthesis of the $\mathrm{Ir}-\mathrm{H}$ species, 5 routes were investigated for the hydride transfer step. If the hydride formation may proceed by an ion-pair mechanism, the transfer of the hydride to the iminium shall occur directly through an outer sphere mechanism. Though this route is limited by the hydride formation and facilitated by electrostatic interactions, this pathway is the most favourable to lead to the amine product. Calculations were also performed considering a methanol molecule for both steps. A significant energy drop of the ion pair transition state was shown due to its stabilisation via hydrogen bonding.

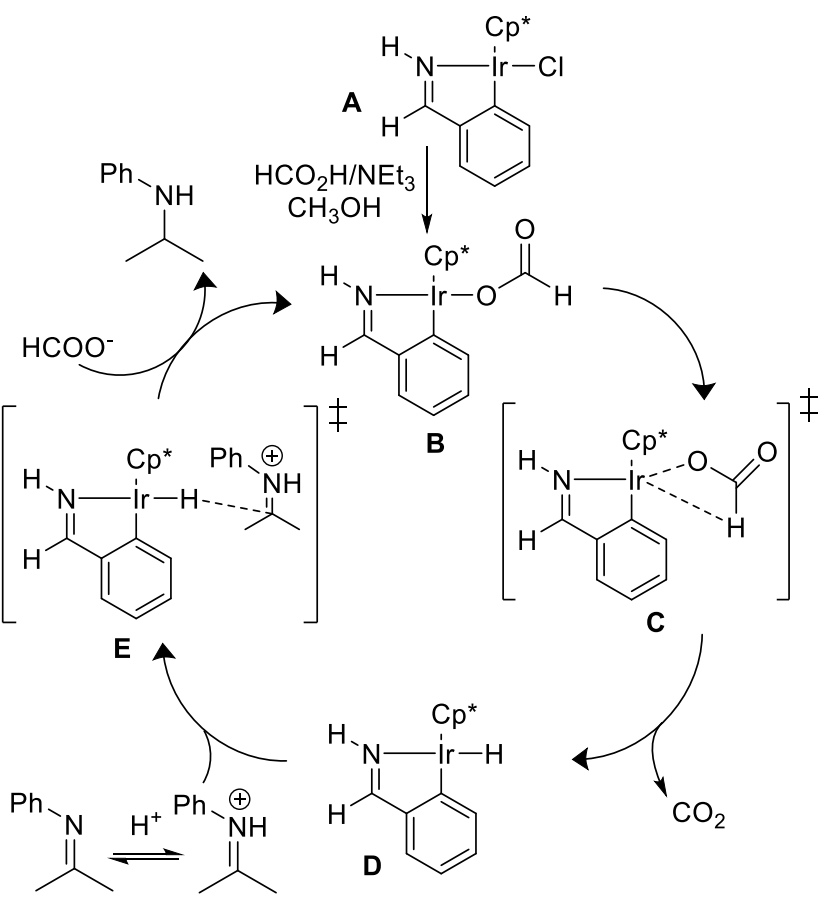

Figure 1. Mechanism of imine hydrogenation with formic acid. ${ }^{[11]}$

Half-sandwich iridium(III) metallacycles have also been applied by Xiao et al. to catalyse the transfer hydrogenation of a range of carbonyl compounds for the preparation of relevant functionalised secondary alcohols (Scheme 3). ${ }^{[12]}$

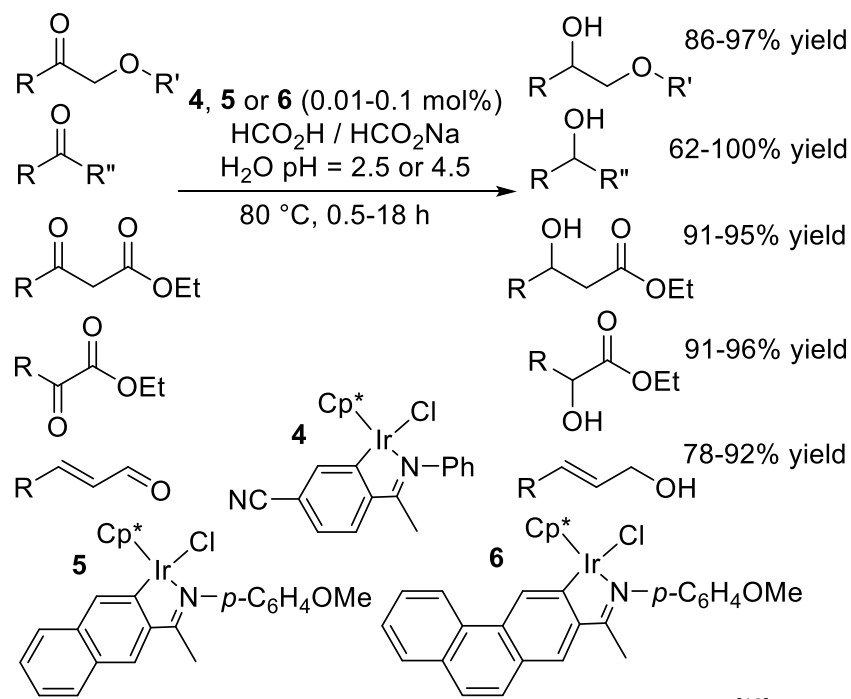

Scheme 3. Transfer hydrogenation of various carbonyl compounds. ${ }^{[12]}$

The attractiveness of this protocol relies on low catalyst loadings, the use of formate as the hydrogen source and of a water medium. Following a ligand screening, two catalysts emerged as the most efficient for the hydrogenation of a wide range of 
substrates such as $\beta$-keto ethers, $\alpha$-substituted ketones, $\alpha$ and $\beta$-keto-esters, and $\alpha, \beta$-unsaturated aldehydes, presenting a great application potential for the synthesis of high added value compounds (Scheme 3).

Imino based half-sandwich iridacycle $\mathbf{5}$ was also versatile when applied under identical catalytic conditions to the transfer hydrogenation of various $\mathrm{N}$-heterocycles in water (Scheme 4). ${ }^{[13]}$ The reaction is applicable to a large scope of $\mathrm{N}$-heterocycles, even on a $35 \mathrm{~g}$ scale, and demonstrated excellent functional group compatibility. The mechanism of the reaction was studied through deuterium labelling experiments. Competitive 1,2- and 1,4-hydride addition pathways were observed with stereoelectronic attributes of the substrate and the catalyst affecting their rate.

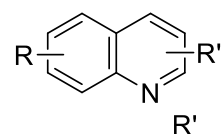

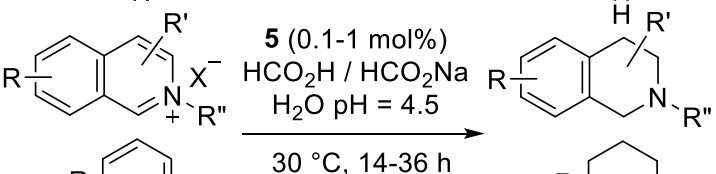

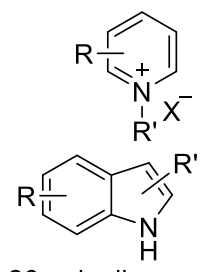

$30{ }^{\circ} \mathrm{C}, 14-36 \mathrm{~h}$<smiles>[R]C1CCCNC1</smiles>
' $\mathrm{R}^{\prime}$<smiles>[R]C1CCCC1</smiles>

$62-98 \%$ yield

$72-99 \%$ yield $30-96 \%$ yield $82-99 \%$ yield

16 isoquinolinium and pyridinium salts 7 indoles

6 other $\mathrm{N}$-heterocycles and imines

Scheme 4. Transfer hydrogenation of $\mathrm{N}$-heterocycles. ${ }^{\left[{ }^{13]}\right.}$

Asymmetric transfer hydrogenation of ketones and ketimines has been reported by Pfeffer, De Vries et al. using half-sandwich iridacycle 7 as catalyst (Scheme 5). ${ }^{[14 a]}$ Alcohols and amines were obtained in low to high yields with rather high enantioselectivities.

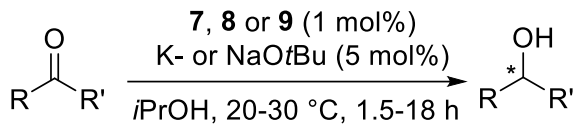

$\mathrm{R}=$ aryl, alkyl $\mathrm{R}^{\prime}, \mathrm{R}^{\prime \prime}=$ alkyl cat. 7: $24-91 \%$ yield, $74-96 \%$ ee cat. 8 or $9: 23-99 \%$ yield, $2-58 \%$ ee

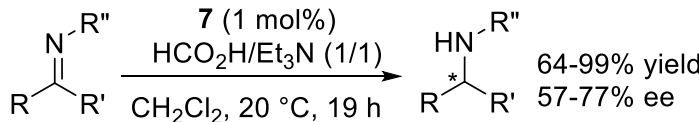

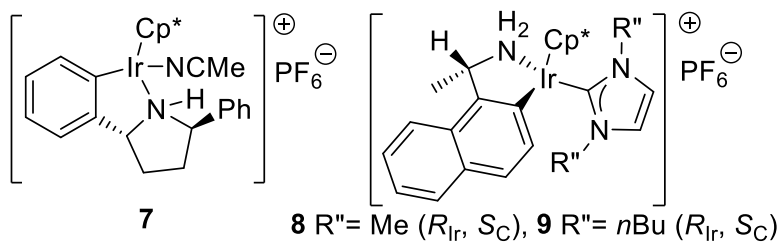

Scheme 5. Asymmetric transfer hydrogenation of alkyl and aryl ketones. ${ }^{[14]}$ Later, Mata et al. reported chiral at metal half-sandwich iridium(III) metallacycles 8 and $\mathbf{9}$ bearing an N-heterocyclic carbene ligand and a chelated primary (S)-[1-(1naphthyl)ethyl]amine (Scheme 5). ${ }^{14 b]}$ These complexes catalysed the asymmetric transfer hydrogenation of ketones in low to high yields with low to average enantioselectivities depending on the bulkiness of the N-heterocyclic carbene ligand. DFT calculations suggested a concerted one-step mechanism based on a direct hydrogen transfer via a highly ordered transition state centered at the iridium amido group.

\subsection{Reductive amination}

The potential of half-sandwich iridium(III) metallacycles has also been examined to catalyse reductive amination reactions. Under the hydrogen transfer conditions previously described, the first example of production of pyrrolidinones from levulinic acid derivatives was reported by Xiao et al. (Scheme 6). ${ }^{[15]}$ Electron donating methoxy groups on the aryl residues of the ligand promoted reactivity of catalyst 10 . The transformations could also be carried out in methanol with $\mathrm{HCOOH} / \mathrm{Et}_{3} \mathrm{~N}$ azeotrope as a hydrogen source. 6-membered $\mathrm{N}$ heterocycles could also be obtained by applying this methodology to 5-oxohexanoic acid.

$$
\begin{aligned}
& 10(0.05 \mathrm{~mol} \%) \\
& \text { - Aromatic amines: } 9 \text { examples, } 72-94 \% \text { yield } \\
& \mathrm{R}=\text { phenyl with alkyl, O-alkyl or halide substituents } \\
& \text { - Aliphatic amines: 8 examples, } 73-96 \% \text { yield } \\
& \mathrm{R} \text { = benzyl, } n \text {-octyl, } n \text {-undecyl }
\end{aligned}
$$

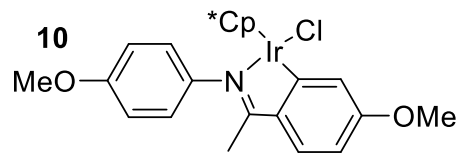

Scheme 6. Synthesis of pyrrolidinones from levulinic acid. ${ }^{[15]}$

Reductive amination of simple ketones and aldehydes in water or methanol has also been described under transfer hydrogenation conditions (Scheme 7). ${ }^{[16]}$

$$
\begin{aligned}
& 5(0.1 \mathrm{~mol} \%) \\
& 15 \text { aromatic and aliphatic amines with: } \\
& \text { - } 15 \text { aromatic ketones in } 2-64 \mathrm{~h}: \\
& \text { - } 14 \text { aliphatic ketones in } 2-48 \mathrm{~h}:
\end{aligned}
$$

Scheme 7. Reductive amination of carbonyl compounds in water. ${ }^{[16]}$

Half-sandwich iridium(III) metallacycle $\mathbf{5}$ was the most appropriate catalyst for these reactions. Best activities and chemoselectivities were achieved in water when the $\mathrm{pH}$ was set to 4.8. It is worth noting all examples given above are also $\mathrm{pH}$ dependent with narrow acidic windows for transfer hydrogenation performed in water. The reaction was found to proceed 6 times faster under aqueous conditions than in $\mathrm{MeOH}{ }^{[16]}$ Interestingly, the reduction of $\beta$-keto esters was also explored, providing access to the corresponding amino acids. An increased activity was observed with aldehydes by comparison with ketone substrates. By applying catalyst 5 to the reductive amination of benzaldehyde with $p$-anisidine on a $250 \mathrm{mmol} \mathrm{scale,}$ 
a $95 \%$ yield was obtained in 48 hours achieving a very high Substrate/Catalyst ratio of $1 \times 10^{5} .{ }^{[16]}$

The direct synthesis of primary amines via reductive amination of ketones and aldehydes was also reported using ammonium formate. ${ }^{[16 b, 17]}$ The latter acted as a source of both ammonia and proton to lead to an iminium intermediate which was then hydrogenated (Scheme 8) ${ }^{[17]}$ Catalyst 5 was used with a large scope of carbonyl compounds to produce various primary amines. It is worth to note the reaction of an $\alpha, \beta$ unsaturated ketone furnished a saturated amine. The authors suggested a 1,4-reduction pathway occurred first as it has frequently been observed in transfer hydrogenation. The catalytic system was also investigated for use in the synthesis of non-natural $\alpha$-amino acids from $\alpha$-keto acids.

$$
\begin{aligned}
& \text { 24 Aromatic ketones: } \\
& \text { 10 Aliphatic ketones: } \\
& 7 \text { } \beta \text {-keto ethers: } \\
& 7 \text { a-keto acids: }
\end{aligned}
$$

Scheme 8. Direct reductive amination of carbonyl compounds for the production of primary amines. ${ }^{[17]}$

\section{Dehydrogenation}

The ability of half-sandwich iridium(III) metallacycles to catalyse hydrogenation and transfer hydrogenation reactions led researchers to examine their potential in dehydrogenation reactions.

\subsection{Alcohols and formic acid dehydrogenation}

Following preliminary investigations, Yamaguchi et al. developed iridium(III) metallacycles based on cooperating 2hydroxy $\mathrm{C}-\mathrm{N}$ chelate ligands. Complex $\mathbf{1 1}$ was shown to catalyse efficiently the oxidant free dehydrogenative oxidation of both primary and secondary alcohols (Scheme 9). ${ }^{[18 a, b]}$ An hydrido iridium complex was found to be involved in the catalytic reaction. Subsequently, Albrecht et al. prepared the bimetallic iridacycle 12 based on a bridging triazolylidene ligand to perform such selective reactions using stronger conditions. ${ }^{[18 c]}$

A seminal work from Fukuzumi et al. reported the application of a pyrazol based iridium(III) metallacycle as a functional mimic of alcohol dehydrogenase (ADH) to catalyse in water the combined dehydrogenation of alcohols and hydrogenation of oxidized $\beta$-nicotinamide adenine dinucleotide $\left(\mathrm{NAD}^{+}\right)$(Scheme 10). ${ }^{[19]}$ In a basic aqueous solution, aquo complex 13 was initially shown to be equilibrated with complex 14 and hydroxo complex 15. ${ }^{[19 a]}$ Interestingly, complex 15 catalysed the dehydrogenation of alcohols and led to iridium hydrido species 16 which could subsequently reduce $\mathrm{NAD}^{+}$ molecules with a turnover frequency (TOF) up to $18 \mathrm{~h}^{-1}$ and regenerate complex $15 .^{[19 b]}$

$$
\begin{aligned}
& 11(2 \mathrm{~mol} \%) \\
& \mathrm{NaHCO}_{3}(5 \mathrm{~mol} \%)
\end{aligned}
$$

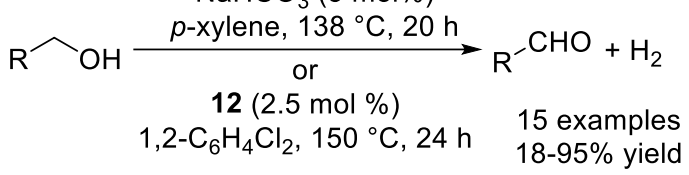

$$
\begin{aligned}
& \mathrm{R}=\text { aryl, alkyl }
\end{aligned}
$$

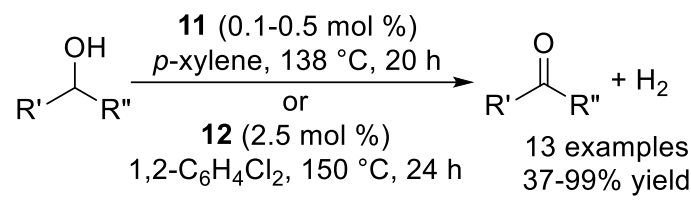

$\mathrm{R}^{\prime}=$ aryl or alkyl, $\mathrm{R}^{\prime \prime}=$ alkyl

$\mathrm{R}^{\prime}, \mathrm{R}^{\prime \prime}=$ cyclohexyl, cycloheptyl<smiles></smiles>

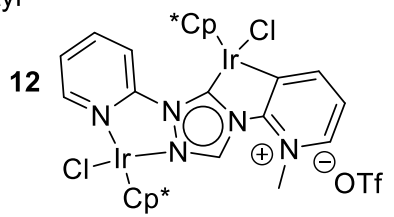

Scheme 9. Dehydrogenation of primary and secondary alcohols. ${ }^{[18]}$

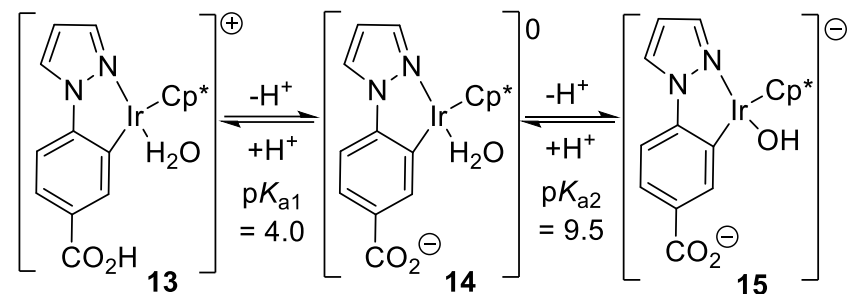

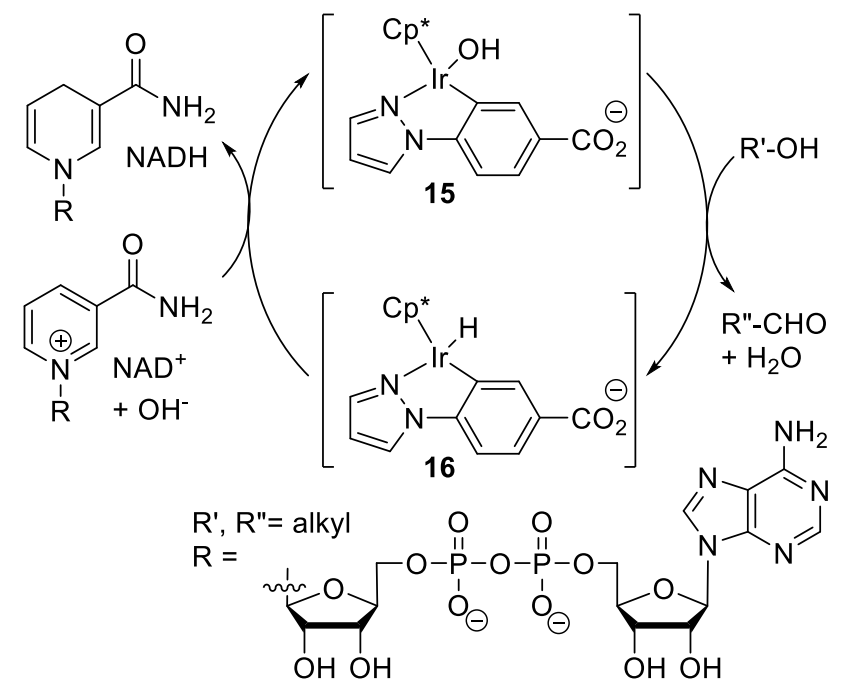

Scheme 10. Dehydrogenation of primary alcohols and hydrogenation of oxidized $\beta$-nicotinamide adenine dinucleotide $\left(\mathrm{NAD}^{+}\right){ }^{[19]}$

\section{2. $\mathrm{N}$-heterocycles dehydrogenation}

In 2013, Xiao et al. used half-sandwich iridium(III) metallacycles to catalyse the acceptorless dehydrogenation of a variety of benzofused $\mathrm{N}$-heterocycles in 2,2,2-trifluoroethanol (TFE) (Scheme 11). ${ }^{[20 a]}$ Tetrahydroisoquinolines and tetrahydro$\beta$-carbolines which do not easily undergo dehydrogenation due to formation of stable imine intermediates were also tolerated. The catalytic dehydrogenation of a primary alcohol containing substrate $\left(\mathrm{R}_{1}=2-\mathrm{CH}_{2} \mathrm{OH}\right)$ showed the chemoselective nature of this catalyst. Subsequently, Xiao et al. highlighted the potential of this catalytic system by demonstrating the dehydrogenation 
process in the synthesis of Harmine, a major $\beta$-carboline alkaloid. ${ }^{[20 a]}$ Following these results, regioselective acceptorless dehydrogenative couplings of 2-Me $\mathrm{N}$-heterocycles were further developed to afford functionalised quinolines, phenanthrolines, and indoles. These reactions generated in-situ nucleophilic enamines which could react with various electrophiles. A further cascade process was developed by combining these dehydrogenative couplings with Friedel-Crafts additions. ${ }^{[20 b]}$<smiles>[R]CNc1cc[R17]cc1[X]</smiles><smiles>[R17][R]1:[X]c2c[R17]ccc2nc1</smiles>

20 examples, $62-97 \%$ yield

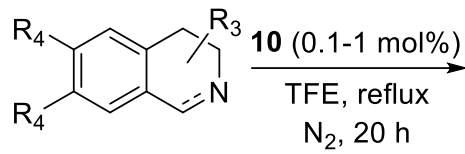

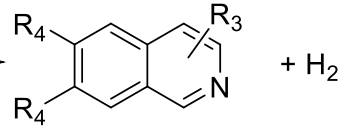
13 examples, $30-96 \%$ yield<smiles></smiles>

$\mathrm{X}=\mathrm{N}, \mathrm{C}$

$\mathrm{R}_{1}=\mathrm{H}$, 2-Me, 3-Me, 4-Me, 2- $\mathrm{CH}_{2} \mathrm{OH}, 2-\mathrm{Ph}, 3-\mathrm{Ph}$

$\mathrm{R}_{2}=\mathrm{H}, \mathrm{Me}, \mathrm{OMe}, \mathrm{F}, \mathrm{Cl}, 5-\mathrm{Me}, 6-\mathrm{Me}$

$\mathrm{R}_{3}=\mathrm{H}, 1-\mathrm{Me}$, 1-iPr, 3-Me, 1-tBu, 1-cyclohexyl, 1-Ph<smiles>c1ccc2c(c1)Cc1ccccc1N2</smiles><smiles>c1ccc2c(c1)CC1CCCCC1N2</smiles><smiles>c1ccc2c(c1)CCC(C1CCc3ccccc3N1)N2</smiles>

$\mathrm{R}_{4}=\mathrm{H}, \mathrm{OMe} \quad \mathrm{R}_{6}=\mathrm{H}, 2-\mathrm{Me}, 3-\mathrm{Me}, 2-\mathrm{Ph}$

$\mathrm{R}_{5}=\mathrm{Ph}, \mathrm{Me} \quad \mathrm{R}_{7}=\mathrm{H}, \mathrm{OMe}, \mathrm{Cl}$

Scheme 11. Acceptorless dehydrogenation of $\mathrm{N}$-heterocycles. ${ }^{[20 \mathrm{a}]}$

\subsection{Amine alkylation}

Based on results related to imine reduction and dehydrogenation (see above), Xiao et al. reported the application of half-sandwich iridium(III) metallacycles to catalyse the amine alkylation with alcohols or amines under rather mild conditions (Scheme 12). ${ }^{[21]}$

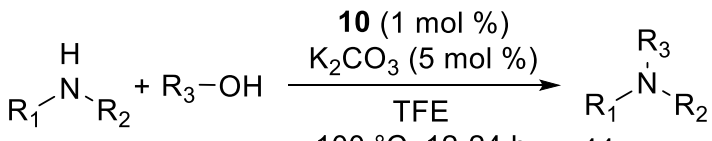

$$
\begin{aligned}
& 100{ }^{\circ} \mathrm{C}, 12-24 \mathrm{~h} \quad 44 \text { examples } \\
& \mathrm{R}_{1}, \mathrm{R}_{2}=\text { aryl, alkyl } \\
& \mathrm{R}_{3}=\text { benzyl, heptyl, undecanyl, Et, Me... } \\
& 19-95 \% \text { yield } \\
& 10(1 \mathrm{~mol} \%)
\end{aligned}
$$

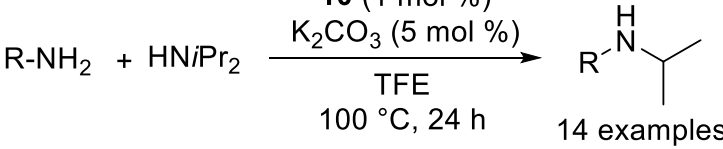

$$
\begin{aligned}
& 19-99 \% \text { yield }
\end{aligned}
$$

Scheme 12. Alkylation of amines with either alcohols or amines. ${ }^{[21]}$

2,2,2-trifluoroethanol (TFE) was found to be crucial for the reaction to proceed, as no reaction was observed with any other solvent. Alkylation of anilines and cyclic amines could be performed with various alcohols including methanol. The use of diols allowed the synthesis of several morpholine, piperidine, and pyrrole based heterocycles. Furthermore, under the same reaction conditions, the cross-coupling of amines led to secondary amines in good yields using diisopropylamine and various anilines (Scheme 12).

\section{Oxydation, racemization, resolution}

Before the successful application of half-sandwich iridium(III) metallacycles bearing $\mathrm{C}-\mathrm{N}$ chelate ligands to hydrogenation and dehydrogenation processes, such catalysts had been successfully applied to alcohol oxidation reactions.

\subsection{Aerobic alcohol oxidation}

Ikariya et al. used amido based half-sandwich iridium(III) metallacycles to catalyse the dehydrogenative oxidation of alcohols with molecular oxygen as the hydrogen acceptor. ${ }^{[22}$ They observed an amine-hydrido iridacycle was dehydrogenated by $\mathrm{O}_{2}$ from air to lead to the corresponding amido iridacycle and water. This reactivity allowed them to apply, for the first time, chiral bifunctional half-sandwich iridium(III) metallacycles to catalyse the kinetic resolution of racemic alcohols through aerobic oxidation of alcohols (Scheme 13). Catalyst screening showed the crucial role played by the $\mathrm{NH}$ moiety in the initiation of $\mathrm{O}_{2}$ activation. The reaction appeared to be sensitive to altering substrates (redox properties), chiral catalyst structure, and small changes in reaction conditions such as solvent and dilution.

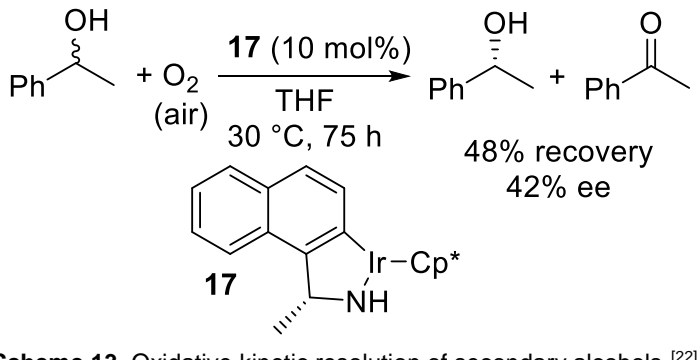

This was the first time aerobic kinetic resolution of racemic secondary alcohols had been performed efficiently using molecular oxygen as the hydrogen acceptor and with defined chiral bifunctional amido half-sandwich iridium(III) metallacycles as catalysts. However, the most selective catalyst was not a metallacycle but an iridium(III) complex based on $\mathrm{N}$-mesyl diphenylethylenediamine ligand (46\% recovery, $>99 \%$ ee),

Ikariya et al. proceeded to expand the applications of halfsandwich iridacycles bearing achiral $\mathrm{C}-\mathrm{N}$ chelate ligands, derived from benzylic amines, to the aerobic oxidation of primary and secondary alcohols (Scheme 14 and 15).[23] Again, the bifunctionality of the catalytic metal- $\mathrm{NH}$ unit was shown to enable the dehydrogenation of secondary alcohols to ketones using oxygen as hydrogen acceptor (Scheme 14). Under similar conditions, amine based catalyst 19 allowed oxidation of primary alcohols into esters through an oxidative dimerization pathway (Scheme 15). 


$$
\begin{aligned}
& \stackrel{\mathrm{R}}{1}_{\mathrm{R}_{2}}^{\mathrm{OH}}+\underset{(\text { air })}{\mathrm{O}_{2}} \underset{30^{\circ} \mathrm{C}, 3-6 \mathrm{~h}}{\stackrel{18(10 \mathrm{~mol} \%)}{\mathrm{THF}}}+\mathrm{R}_{1} \overbrace{\mathrm{R}_{2}}^{\mathrm{O}}+\mathrm{H}_{2} \mathrm{O} \\
& \text { Secondary alcohol Yield } \\
& \mathrm{R}_{1}, \mathrm{R}_{2}=\text { aryl, alkyl } \quad 55-87 \% \\
& \mathrm{R}_{1}=\mathrm{Ph}, \mathrm{R}_{2}=\mathrm{COPh}, \mathrm{COHPh} 10-34 \% \\
& \text { 2-cyclohexen-1-ol } \\
& \text { trans-1,2-cyclohexanediol }
\end{aligned}
$$

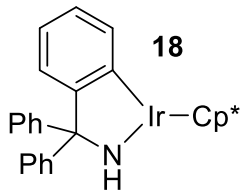

Scheme 14. Aerobic oxidation of secondary alcohols. ${ }^{[23]}$

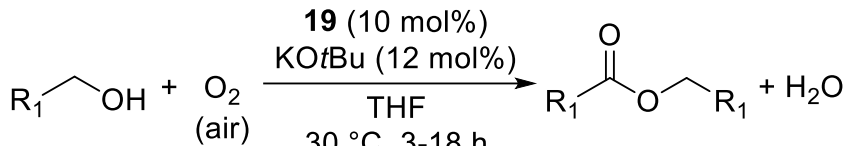

$$
\begin{aligned}
& \mathrm{R}_{1}=\text { aryl, alkyl }
\end{aligned}
$$

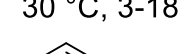<smiles>Cl[I-]1(Cl)NC(c2ccccc2)(c2ccccc2)c2ccccc21</smiles>

Scheme 15. Aerobic oxidation of primary alcohols. ${ }^{[23]}$

\subsection{Racemisation of alcohols and amines}

Feringa, De Vries et al. applied selected half-sandwich iridacycles to the racemisation of chiral alcohols and amines. ${ }^{[24]}$ Activation of iridium(III) pre-catalyst $\mathbf{2 1}$ with a base led to the racemisation of alcohols and some amounts of ketones (Scheme 16), while the non-activated complex 22 was selective for the effective racemisation of amines (Scheme 17).

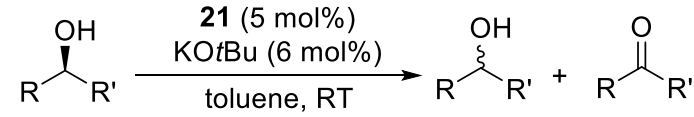

ee $>99 \%$ time for racemisation $100-80 \%$ side product $5 \mathrm{~min}-24 \mathrm{~h} \quad$ yield $\quad 0-20 \%$ yield

$\mathrm{R}=$ aryl, alkyl

$\mathrm{R}^{\prime}=$ alkyl, $\mathrm{CH}_{2} \mathrm{Cl}$

9 examples

$\mathrm{R}, \mathrm{R}^{\prime}$ = indane

Scheme 16. Racemisation of alcohols. ${ }^{[24]}$

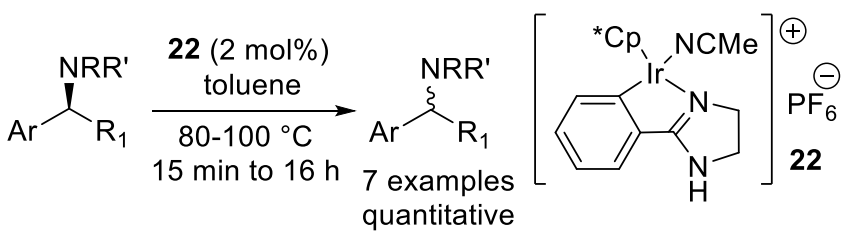

$\mathrm{Ar}=\mathrm{Ph}, \mathrm{R}_{1}=\mathrm{Me}: \mathrm{R}, \mathrm{R}^{\prime}=\mathrm{H}$ or $\mathrm{Me}, \mathrm{R}=\mathrm{H}$ and $\mathrm{R}^{\prime}=\mathrm{Me}, \mathrm{Bn}$ $\mathrm{Ar}, \mathrm{R}_{1}=$ indane, tetrahydronaphtalene, 1-Me tetrahydroquinoline

Scheme 17. Racemisation of amines. ${ }^{[24]}$

\subsection{Dynamic Kinetic Resolution of racemic secondary alcohols}

In 2008, Feringa, de Vries et al. reported the first direct stereoselective transformation of racemic $\beta$-haloalcohols into enantiomerically enriched epoxides via a DKR process in the presence of a half-sandwich iridium(III) metallacycle as the catalyst (Scheme 18). ${ }^{[25]}$ The latter was used in conjunction with a haloalcohol dehalogenase (Hhec) variant possessing two mutations in order to increase enzyme stability towards oxidation (Cys153Ser) and enantioselectivity for aromatic substrates
(Trp249Phe). A biphasic medium was required in order to trap the Brønsted acid released during ring closure to the epoxide. Although the bromoalcohol substrates often resulted in higher yields of products, increased enantioselectivities were obtained with the chloride derivatives, as the rate of the uncatalysed ring closure of chloroalcohols was lower than that for bromoalcohols.

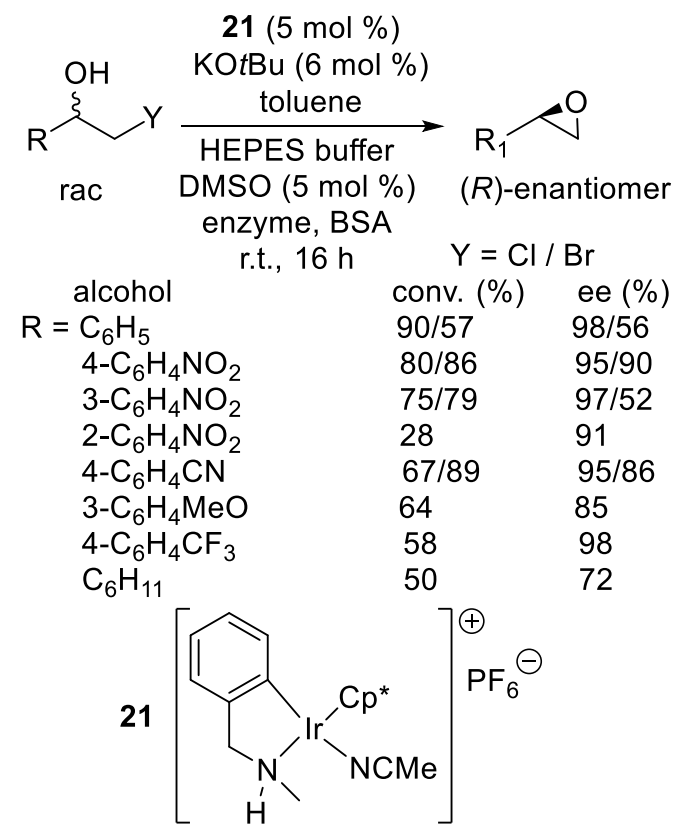

Scheme 18. Chiral epoxides via DKR of $\beta$-haloalcohols. ${ }^{[25]}$

In 2012, Ikariya et al. explored further the potential of their bifunctional amido-iridium catalysts in a chemo-enzymatic system. The dynamic kinetic resolution (DKR) of racemic alcohols combining $\mathbf{2 0}$ with Candida antarctica lipase B (CALB) provided a range of chiral acetates (Scheme 19). ${ }^{[26]}$

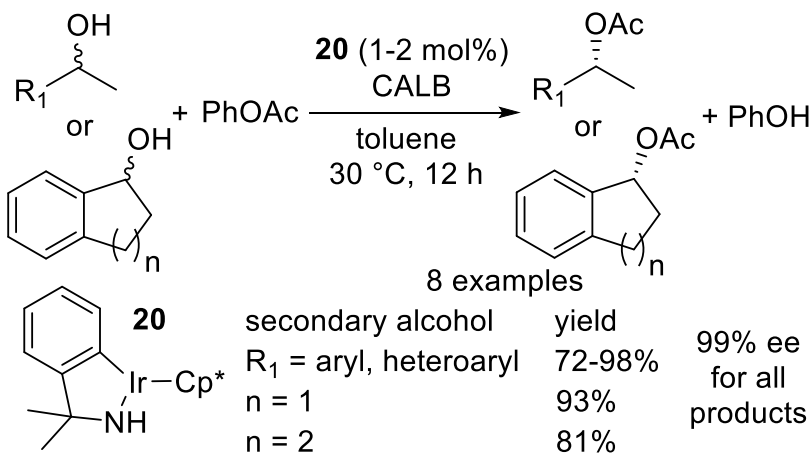

Scheme 19. Optically pure acetates through DKR of alcohols. ${ }^{[26]}$

Interestingly, such a catalytic system combined a metalcatalysed racemisation with an enantioselective enzymatic transesterification at room temperature, in the absence of a base and with an equimolar amount of acyl donor. All 8 substrates were converted to acetates with $99 \%$ ee and 7 resulted in yields over $80 \%$. These significant achievements present an interesting route for the synthesis of optically pure acetates from racemic secondary alcohols and highlight the compatibility of such bifunctional iridium catalysts with chemo-enzymatic conditions. 


\section{Hydrofunctionalizations}

\subsection{Hydrosilylation}

A study on the hydrosilylation of imines employing halfsandwich iridium(III) metallacycles was reported by Michon et al (Scheme 20). ${ }^{[27]}$

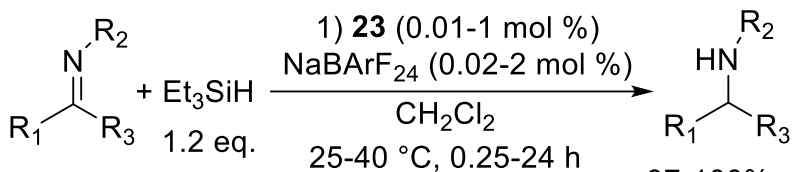

$$
\text { 2) } \mathrm{H}_{2} \mathrm{O}, \mathrm{H}^{+}
$$

$37-100 \%$ yield

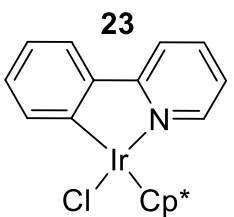

ketimines (12 examples)

$\mathrm{R}_{1}, \mathrm{R}_{2}, \mathrm{R}_{3}=$ aryl, alkyl

aldimines (14 examples)

$\mathrm{R}_{1}=$ aryl, heteroaryl, alkyl, $\mathrm{CH}=\mathrm{CHPh}$

$\mathrm{R}_{2}=$ aryl, alkyl

$\mathrm{R}_{3}=\mathrm{H}$

Scheme 20. Hydrosilylation of imines. ${ }^{[27]}$

Activation of half-sandwich iridium(III) metallacycle 23 via displacement of the chloride ligand was required and sodium tetrakis[(3,5-trifluoromethyl)phenyl]borate $\left(\mathrm{NaBArF}_{24}\right)$ proved to be the most effective in displacing the halide and affording an active catalyst. The authors demonstrated the less coordinating the anion was, the higher the yields were. The catalytic activity of the tricarbonyl chromium bound half-sandwich iridium(III) metallacycle was also monitored in the hydrosilylation of imines, but afforded lower yields. The catalyst appeared to be very active at mild temperatures affording for example $90 \%$ yield of the amine issued from the hydrosilylation of $\mathrm{N}$ phenylethylideneaniline with $0.01 \mathrm{~mol} \%$ cat. in 24 hours. A broad range of aldimines and ketimines were reduced under mild conditions with low catalyst loading (Scheme 20). Further analysis of the active species showed the in-situ generated iridacycles to be more active than the isolated cationic complexes. In-situ NMR experiments showed several mono- and dihydride iridium species without any coordinated molecular hydrogen.

\subsection{Tandem hydroamination-hydrosilylation}

In 2012, Djukic et al. reported a seminal application of halfsandwich iridium(III) metallacycles to catalyse a tandem hydroamination-hydrosilylation reaction (Scheme 21). ${ }^{[28]}$ Following a study on the stoechiometric insertion of phenylacetylene into C-Ir bonds of some iridacycles, the authors reported the transformation of terminal aromatic alkynes to racemic $\mathrm{N}$-phenyl, 1-arylethylamines in a 'one-pot' reaction using an iridacycle bound by an electron withdrawing tricarbonylchromium. Such half-sandwich iridacycles were shown to catalyse the hydroamination of terminal alkynes into $\mathrm{N}$ phenylimines and the hydrosilylation of the latter into benzylamines, both as two separate reactions and in a tandem 'one-pot' fashion. The efficiency of the catalyst in the hydrosilylation process was attributed to the involvement of an Ir-mono-hydride intermediate. ${ }^{[19,29]}$

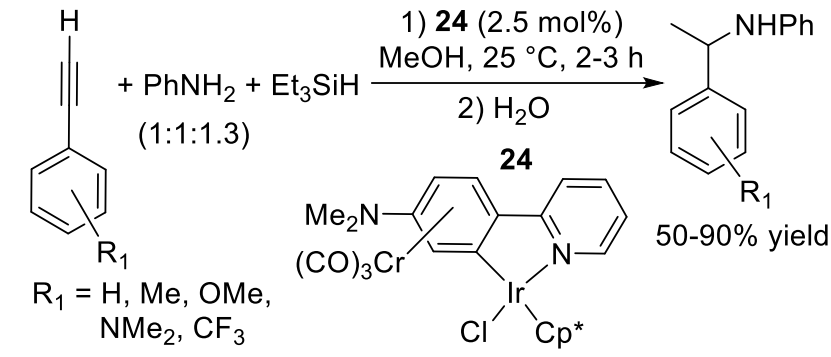

Scheme 21. Tandem hydroamination-hydrosilylation. ${ }^{[28]}$

\section{Conclusion}

The application of pentamethylcyclopentadienyl iridium(III) metallacycles in homogeneous catalysis is a rapidly expanding area of research. Through the development of novel catalysts tailored to facilitate a wide range of organic transformations, the potential of such complexes continues to be exposed. Hence, well defined half-sandwich iridacycles have been reported in the production of several related chemical reactions, e.g. mainly hydro- and dehydrofunctionalizations, with broad substrate scopes. These half-sandwich iridacycle catalysts have shown high activities under mild conditions and at low catalyst loadings. In most cases, they offer environmentally and economically beneficial routes towards fine chemicals, since novel and alternative protocols for existing processes have been reported.

While half-sandwich iridium(III) metallacycles are by now clearly well-established homogeneous catalysts, fundamental developments in this area of research are appearing more frequently, and many recent reports predict further promising advancements in the near future. Key studies and modifications of the $\mathrm{C}-\mathrm{N}$ chelate ligands are needed. They may rationalize and improve catalyst activity, allow metal ligand cooperation and enable the application of recycling methods and processes.

\section{Acknowledgements}

The University of Edinburgh, ENSCL and E.U. are thanked for an Erasmus+ fellowship (K.M.). The Ministère de l'Enseignement Supérieur et de la Recherche and Région NordPas de Calais are acknowledged for a PhD fellowship (Y.C.). CNRS, Chevreul Institute (FR 2638), Ministère de l'Enseignement Supérieur et de la Recherche, Région Nord Pas de Calais and FEDER are acknowledged for supporting and funding partially this work.

Keywords: iridium, metallacycle, half-sandwich, organometallics, homogeneous catalysis.

[1] a) J. P. Kleiman, M. Dubeck, J. Am. Chem. Soc. 1963, 85, 1544-1545 b) A. D. Ryabov, Chem. Rev. 1990, 90, 403-424; c) M. Albrecht, Chem. Rev. 2010, 110, 576-623.

[2] Y.-F. Han, G.-X. Jin, Chem. Soc. Rev. 2014, 43, 2799-2823.

[3] a) J. Li, S. De Sarkar, L. Ackermann, Top. Organomet. Chem. 2016, 55, 217-257; b) Z. Huang, H. N. Lim, F. Mo, M. C. Young, G. Dong, Chem. Soc. Rev. 2015, 44, 7764-7786; c) N. Kuhl, N. Schroder, F. Glorius Adv. Synth. Catal. 2014, 356, 1443-1460; d) M. Zhang, Y. Zhang, X. Jie, H. Zhao, G. Li, W. Su, Org. Chem. Front. 2014, 1, 843-895; e) S Tani, T. N. Uehara, J. Yamaguchi, K. Itami, Chem. Sci. 2014, 5 , $123-135$. 
[4] J. K. Liu; X. F. Wu, J. A. Iggo, J. L. Xiao, Coord. Chem. Rev. 2008, 252, 782-809.

[5] For some recent reviews, see: a) E. Meggers, Chem. Commun. 2015 51, 3290-3301; b) R. A. Angnes, Z. Li, C. R. D. Correia, G. B Hammond, Org. Biomol. Chem. 2015, 13, 9152-9167; c) J. W. Beatty, C. R. J. Stephenson, Acc. Chem. Res. 2015, 48, 1474-1484; d) C. K. Prier, D. A. Rankic, D. W. C. MacMillan, Chem. Rev. 2013, 113, 5322 5363; e) K. K.-W. Lo, S. P.-Y. Li, K. Y. Zhang, New J. Chem. 2011, 35 265-287; f) J. M. R. Narayanam, C. R. J. Stephenson, Chem. Soc. Rev. 2011, 40, 102-113.

[6] a) Z. Liu, P. J. Sadler, Acc. Chem. Res. 2014, 47, 1174-1185; b) I. Omae, Coord. Chem. Rev. 2014, 280, 84-95; c) C.-H. Leung, S. Lin H.-J. Zhonga, D.-L. Ma, Chem. Sci. 2015, 6, 871-884; d) S. Medicia, M. Peana, V. M. Nurchi, J. I. Lachowicz, G. Crisponi, M. A. Zoroddu, Coord. Chem. Rev. 2015, 284, 329-350.

[7] For examples: a) Y. Ikeda, S. Kodama, N. Tsuchida, Y. Ishii, Dalton Trans. 2015, 44, 17448-17452; b) G. Choi, H. Tsurugi, K. Mashima, J. Am. Chem. Soc. 2013, 135, 13149-13161; c) T. P. Montgomery, A Hassan, B. Y. Park, M. J. Krische, J. Am. Chem. Soc. 2012, 134 11100-11103; d) D. L. Davies, O. Al-Duaij, J. Fawcett, K. Singh, Organometallics 2010, 29, 1413-1420; e) L. Li, Y. Jiao, W. W Brennessel, W. D. Jones, Organometallics 2010, 29, 4593-4605.

[8] a) T. Suenobu, Y. Isaka, S. Shibata, S. Fukuzumi, Chem. Commun. 2015, 51, 1670-1672; b) T. Suenobu, S. Shibata, S. Fukuzumi, Catal. Sci. Technol. 2014, 4, 3636-3639; c) J. H. Barnard, C. Wang, N. G. Berry, J. Xiao, Chem. Sci. 2013, 4, 1234-1244; d) S. Shibata, T. Suenobu, S. Fukuzumi, Angew. Chem. 2013, 125, 12553-12557 Angew. Chem. Int. Ed. 2013, 52, 12327-12331; e) W. Iali, P. Petrović, M. Pfeffer, S. Grimme, J.-P. Djukic, Dalton Trans. 2012, 41, 1223312243; f) Y. Maenaka, T. Suenobua, S. Fukuzumi, Energy Environ. Sci. 2012, 5, 7360-7367.

[9] J. Wu, J. H. Barnard, Y. Zhang, D. Talwar, C. M. Robertson, J. Xiao, Chem. Commun. 2013, 49, 7052-7054.

[10] a) B. Villa-Marcos, W. Tang, X. Wu, J. Xiao, Org. Biomol. Chem. 2013, 11, 6934-6939; b) W. Tang, C. Lau, X. Wu, J. Xiao, Synlett 2014, 25 81-84.

[11] H. Y. T. Chen, C. Wang, X. Wu, X. Jiang, C. R. A. Catlow, J. Xiao, Chem. Eur. J. 2015, 21, 16564-16577.

[12] a) Y. Wei, D. Xue, Q. Lei, C. Wang and J. Xiao, Green Chem. 2013, 15, 629-634; b) D. Talwar, X. Wu, O. Saidi, N. P. Salguero, J. Xiao, Chem. Eur. J. 2014, 20, 12835-12842.

[13] D. Talwar, H. L. Yi, E. Durham, J. Xiao, Chem. Eur. J. 2015, 21, 5370 5379.

[14] a) N. Pannetier, J.-B. Sortais, J.-T. Issenhuth, L. Barloy, C. Sirlin, A. Holuigue, L. Lefort, L. Panella, J. G. de Vries, M. Pfeffer, Adv. Synth.
Catal. 2011, 353, 2844-2852; b) S. Sabater, M. Baya, J. A. Mata Organometallics 2014, 33, 6830-6839.

[15] Y. Wei, C. Wang, X. Jiang, D. Xue, J. Li, J. Xiao, Chem. Commun. 2013, 49, 5408-5410.

[16] a) Q. Lei, Y. Wei, D. Talwar, C. Wang, D. Xue, J. Xiao, Chem. Eur. J. 2013, 19, 4021-4029; b) C. Wang, A. Pettman, J. Bacsa, J. Xiao Angew. Chem. 2010, 122, 7710-7714; Angew. Chem. Int. Ed. 2010, 49, 7548-7552

[17] D. Talwar, N. Poyatos Salguero, C. M. Robertson, J. Xiao, Chem. Eur J. 2014, 20, 245-252.

[18] a) K. Fujita, K, N. Tanino, R. Yamaguchi, Org. Lett. 2007, 9, 109-111; b) K. Fujita, T. Yoshida, Y. Imori, R. Yamaguchi, Org. Lett. 2011, 13, 2278-2281; c) M. Valencia, H. Müller-Bunz, R. A. Gossage, M. Albrecht, Chem. Commun. 2016, 52, 3344-3347.

[19] a) Y. Maenaka, T. Suenobu, S. Fukuzumi, J. Am. Chem.Soc. 2012, 134 367-374; b) Y. Maenaka, T. Suenobu, S. Fukuzumi, J. Am. Chem.Soc. 2012, 134, 9417-9427.

[20] a) J. Wu, D. Talwar, S. Johnston, M. Yan, J. Xiao, Angew. Chem. 2013 125, 7121-7125; Angew. Chem. Int. Ed. 2013, 52, 6983-6987; b) D. Talwar, A. Gonzalez-De-Castro, H. Y. Li, J. Xiao, Angew. Chem. 2015 127, 5312-5316; Angew. Chem. Int. Ed. 2015, 54, 5223-5227.

[21] Q. Zou, C. Wang, J. Smith, D. Xue, J. Xiao, Chem. Eur. J. 2015, 21, 9656-9661.

[22] S. Arita, T. Koike, Y. Kayaki, T. Ikariya, Angew. Chem. 2008, 120 2481-2483; Angew. Chem. Int. Ed. 2008, 47, 2447-2449.

[23] S. Arita, T. Koike, Y. Kayaki, T. Ikariya, Chem. Asian J. 2008, 3, 1479 1485

[24] T. Jerphagnon, A. J. A. Gayet, F. Berthiol, V. Ritleng, N. Mršić, A Meetsma, M. Pfeffer, A. J. Minnaard, B. L. Feringa, J. G. de Vries Chem. Eur. J. 2009, 15, 12780-12790.

[25] M. Haak, F. Berthiol, T. Jerphagnon, A. J. A. Gayet, C. Tarabiono, C. P Postema, V. Ritleng, M. Pfeffer, D. B. Janssen, A. J. Minnaard, B. L. Feringa, J. G. de Vries, J. Am. Chem. Soc. 2008, 130, 13508-13509.

[26] Y. Sato, Y. Kayaki, T. Ikariya, Chem. Commun. 2012, 48, 3635-3637.

[27] Y. Corre, W. Iali, M. Hamdaoui, X. Trivelli, J.-P. Djukic, F. AgbossouNiedercorn, C. Michon, Catal. Sci. Tech. 2015, 5, 1452-1458.

[28] W. Iali, F. La Paglia, X.-F. Le Goff, D. Sredojevic , M. Pfeffer, J.-P. Djukic, Chem. Commun. 2012, 48, 10310-10312.

[29] a) C. Scheeren, F. Maasarani, A. Hijazi, J.-P. Djukic, M. Pfeffer, S. D. Zaric, X.-F. LeGoff, L. Ricard, Organometallics 2007, 26, 3336-3345; b) Y. Hu, L. Li, A. P. Shaw, J. R. Norton, W. Sattler, Y. Rong, Organometallics 2012, 31, 5058-5064. 
